\title{
ANALISIS KEBUTUHAN VIDEO PEMBELAJARAN STATISTIKA BERBANTU PROSHOW
}

\author{
${ }^{1}$ Fhela Vhantoria Ningrum \\ 1riavhantoria@gmail.com
}

\section{${ }^{1}$ Universitas Muhammadiyah Kotabumi, Lampung}

\begin{abstract}
Online learning during the COVID-19 pandemic demands quality learning media. One of the learning media is video. Video quality can be improved by editing and setting after the recording is complete. Interesting video shows can eliminate the boredom of online learning for a long period. Especially in learning statistics that require complicated calculations. The purpose of this study is to analyze the needs of statistical learning videos assisted by proshow. This research method is descriptive exploratory. The data comes from the results of a questionnaire of 32 students of SMPN 7 Kotabumi. The results of the study are that students need learning media in the form of learning videos that are easily accessible and interesting so that statistics are easy to understand. The Proshow application can make learning videos give impressive effects.
\end{abstract}

Keyword: Needs Analysis; Proshow; Statistics; Tutorial Video

Abstrak Pembelajaran daring pada masa pandemi covid-19 menuntut media pembelajaran yang berkualitas. Salah satu media pembelajaran adalah video. Kualitas video dapat ditingkatkan dengan proses editing dan setting pasca perekaman selesai. Tayangan video yang menarik dapat menghilangkan kejemuan pembelajaran daring dengan jangka waktu yang cukup lama. Terlebih lagi pada pembelajaran statistika yang syarat dengan perhitungan yang rumit. Tujuan penelitian ini adalah analisis kebutuhan video pembelajaran statistika berbantu proshow. Metode penelitian ini adalah deskriptif eksploratif. Data berasal dari hasil angket 32 siswa SMPN 7 Kotabumi. Hasil penelitian yaitu siswa membutuhkan media pembelajaran berupa video pembelajaran yang mudah diakses dan menarik agar statistika mudah dipahami. Aplikasi Proshow dapat membuat video pembelajaran memberikan efek mengesankan.

Kata kunci: Analisis Kebutuhan; Proshow; Statistika; Video Pembelajaran

\section{PENDAHULUAN}

Salah satu dampak negatif dari pandemi covid-19 bagi pendidikan adalah ketika terjadi kesenjangan antara anak miskin dan kaya. Dimana kebutuhan gadget dan ketersediaan kuota internet sangat penting untuk dapat mengakses sumber belajar saat ini. Sampai pada titik akhirnya harus putus sekolah. Dampak negatif lainnya sulit terkontrolnya ketercapaian akademik dan keterlibatan aktif siswa.

Namun keadaan Pandemi Covid-19 ada dampak positif yang terjadi yaitu dorongan inovasi dalam penggunaan 
teknologi oleh guru (Thomas \& Rogers, 2020). Pengembangan media pembelajaran yang disesuaikan dengan kebutuhan dalam memudahkan pembelajaran daring menjadi salah satu tuntutan yang harus guru lakukan. Pada dasarnya media pembelajaran adalah alat bantu siswa untuk belajar lebih baik (Pakpahan et al., 2020).

Salah satu media pembelajaran adalah video. Sebelum pandemi covid-19, video sudah memiliki banyak kelebihan ketika digunakan sebagai media pembelajaran. beberapa kelebihan video sebagai media pembelajaran adalah fokus lebih terhadap bahan ajar yang ditampilkan, dapat mengakses ulang dan mudah, menjeda dan mengulang materi. Namun keterlibatan siswa menurun tajam saat menonton video selama 6 menit (Guo, Kim, \& Rubin, 2014). Oleh karena itu, produksi video yang baik dapat memacu keterlibatan siswa lebih aktif dalam kurun waktu yang lama.

Dalam proses produksi video pembelajaran dapat menggunakan beberapa software. Software yang dapat membantu editing video agar lebih menarik dan efektif.salah satu software profesional yang direkomendasikan adalah proshow producer. Fitur pada proshow memiliki banyak kelebihan untuk membuat video pembelajaran yang baik. Pada akhirnya tercipta video pembelajaran sebagai sebuah media pembelajaran yang menarik.
Salah satu desain pengembangan media pembelajaran yaitu ADDIE. Terdapat lima tahapan dalam model ADDIE, salah satunya adalah analisis. Pada tahapan analisis, identifikasi kebutuhan siswa diperoleh dari pertanyaan-pertanyaan kuisioner. Beberapa pertanyaan umumnya terkait kebutuhan siswa dalam belajar. Misalkan ketersediaan sumber belajar, strategi pembelajaran, tujuan instruksional, dan apa saja yang diperlukan dalam menyelesaikan proses pembelajaran.

Salah satu fungsi tujuan instruksional sebagai arah cakupan materi pembelajaran. Materi pembelajaran yang dipilih dalam penelitian ini adalah statistika. Tujuan dari penelitian ini adalah analisis kebutuhan video pembelajaran statistika berbantu proshow. Dengan harapan hasil penelitian informasi media pembelajaran yang perlu dikembangkan.

\section{METODE PENELITIAN}

Penelitian deskriptif eksploratif menjadi metode dalam penelitian ini. Pelaksanaan penelitian pada bulan maret 2021 dengan subjek penelitian 32 siswa kelas VIII di SMPN 7 yang dipilih secara random. Data berupa angket analisis kebutuhan video pembelajaran statistika berbantu proshow. Berikut pertanyaan setiap butir angket. 
1. Apakah statistika merupakan mata pelajaran yang penting, namun sulit dipahami?

2. Bagaimana strategi pembelajaran yang anda inginkan untuk membantu belajar?

3. Biasanya sumber belajar dapat anda diperoleh dimana?

4. Apakah media pembelajaran berupa video dapat membantu belajar? Jelaskan alasannya?

5. Berikan saran terkait media pembelajaran yang anda inginkan agar mudah memahami statistika?

\section{HASIL DAN PEMBAHASAN}

Hasil analisis data yang diperoleh dari angket analisis kebutuhan video pembelajaran statistika berbantu proshow diuraikan sebagai berikut. Siswa mengakui pentingnya materi statitika dikarenakan materi wajib di kurikulum nasional. Selain itu, siswa merasa kesulitan dalam memahami statistika. Siswa mengalami kesulitan dalam mengidentifikasi soal dan cara apa yang harus digunakan untuk menyelesaikan soal statistika (Mediyani \& Mahtuum, 2020). Secara garis besar, faktor penyebab kesulitan menyelesaikan masalah statistika adalah keterbatasan pemahaman konsep dasar, kesulitan membuat model matematika yang kemudian memanipulasi dan berakhir pada penarikan kesimpulan (Dewi, Khodijah, \& Zanthy, 2020). Dalam mengatasi kesulitan belajar statistika perlu ada tatacara membuat strategi pembelajaran. Pengembangan strategi dan media pembelajaran dengan melihat kesulitan belajar siswa sangat jarang dilakukan oleh guru (Wijaya, Retnawati, Setyaningrum, Aoyama, \& Sugiman, 2019).

Analisis pertanyaan selanjutnya terkait strategi pembelajaran yang diinginkan siswa. Strategi pembelajaran statistika terdiri dari semua bagian materi statistika dan tatacara pembelajaran. Siswa menginginkan materi pembelajaran ditampilkan secara menarik dan mudah dipahami. Namun pembelajaran daring selama ini, materi pembelajaran berupa slide-slide PPT Powerpoint. Sejalan dengan refleksi dari pembelajaran pada masa pandemi covid-19 saat ini adalah implikasi penggunaan media pembelajaran powerpoint, classroom Response System, kelompok belajar, dan papan tulis (Chiu, 2020).

Selain itu, siswa menginginkan dapat secara berulang mempelajari materi yang telah didapatkan sebelumnya. kelebihan video sebagai media pembelajaran adalah dapat digunakan berulang dan materi dapat ditampilkan bergerak dan bersuara. Selain itu, video dapat di upload pada jaringan internet yang 
senantiasa siswa dapat melihat dan mengaksesnya kapanpun. Cara memperoleh materi tersebut sangat berkaitan dangan sumber belajar yang dipakai untuk menggapai tujuan pembelajaran.

Media pembelajaran berperan sebagai sumber belajar (Cahyadi, 2019). Hal tersebut karena siswa memperoleh pengetahuan baru melalui media pembelajaran. Oleh karena itu. Sumber belajar biasanya diperoleh dari buku paket dan Lembar Kerja Siswa. Namun pandemi covid-19 mengakibatkan pembelajaran daring sehingga sumber belajar didapatkan dari materi yang di upload pada media pembelajaran google classroom. Kelemahan google classroom, guru tidak bisa memantau materi yang diberikan sudah sepenuhnya terbaca oleh siswa (Rahmanto \& Bunyamin, 2020).

Video pembelajaran merupakan salah satu media pembelajaran. Siswa beranggapan bahwa video pembelajaran lebih menarik dan tidak membosankan. Selain itu, video pembelajaran membantu siswa lebih memahami materi pelajaran yang sulit dipahami hanya dengan pemaparan guru saja. Penggunaan video pembelajaran dapat maksimal dengan menyatukan modality dengan content (Brame, 2017). Dengan kata lain, dengan kata lain, penggunaan audio, visual, dan dengan penyesuaian materi dapat meningkatkan pemahaman kognitif siswa.

Media pembelajaran yang diinginkan siswa adalah video dengan tampilan menarik, dan mudah dipahami. Oleh karena itu, video harus melalui proses editing sebelum di upload untuk dibagikan kepada siswa. Proshow merupakan aplikasi dengan ratusan slide dan tool yang dapat membuat video pembelajaran lebih menarik. Selain itu, proshow langsung terintegrasi dengan facebook dan youtube sehingga siswa dapat dengan mudah mengakses materi yang diberikan oleh guru.

\section{KESIMPULAN}

Berdasarkan hasil dan pembahasan penelitian, media pembelajaran perlu dikembangkan di SMPN 7 Kotabumi khususnya pada materi statistika. Video menjadi salah satu media pembelajaran yang dapat yang dikembangkan. Selain itu video membutuhkan bantuan aplikasi proshow guna membuat tampilan menarik dan mudah diakses oleh siswa. Hal tersebut dengan tujuan untuk mempermudah siswa dalam proses pembelajaran daring saat ini. 


\section{DAFTAR RUJUKAN}

Brame, C. J. (2017). ffective Educational Videos: Principles and Guidelines for Maximizing Student Learning from Video ContentEffective Educational Videos: Principles and Guidelines for Maximizing Student Learning from Video Content. CBE_Life Sciences Education, 15(4). https://doi.org/https://doi.org/10.1187/cbe.16-03-0125

Cahyadi, A. (2019). Pengembangan Media dan Sumber Belajar Teori dan Prosedur (1st ed.). Serang: Laksita Indonesia.

Chiu, W.-K. (2020). Implications for the Use of PowerPoint, Classroom Response Systems, Teams, and Whiteboard to Enhance Online Teaching of Chemistry Subjects in Community College. J. Chem. Educ, 97(9), 3135-3139. https://doi.org/https://doi.org/10.1021/acs.jchemed.0c00830

Dewi, D. K., Khodijah, S. S., \& Zanthy, L. S. (2020). Analisis Kesulitan Matematik siswa SMP Pada Materi Statistika. Jurnal Cendekia: Jurnal Pendidikan Matematika, 04(01), 1-7. https://doi.org/https://doi.org/10.31004/cendekia.v4i1.148

Guo, P. J., Kim, J., \& Rubin, R. (2014). How video production affects student engagement: an empirical study of mooc videos. In The Proceedings of the First ACM Conference on Learning, 41-50. New York, NY, USA.

Mediyani, D., \& Mahtuum, Z. A. (2020). Analisis Kesulitan Siswa Dalam Menyelesaikan Soal Materi Statistika Pada Siswa SMP Kelas VIII. Junal Pembelajaran Matematika Inovatif, 3(4), 385. https://doi.org/DOI 10.22460/jpmi.v3i4.385-384

Pakpahan, A. F., Ardiana, D. P. Y., Mawati, A. T., Imarmata, E. B. W., Mansyur, M. Z., Purba, L. L1., ... Iskandar, A. (2020). Pengembangan Media Pembelajaran (1st ed.; A. Karim \& S. Purba, eds.). Retrieved from https://books.google.co.id/books?hl=en\&lr=\&id=lZgQEAAAQBAJ\&oi=fnd\&pg=PA53 $\& d q=$ pengembangan+media\&ots=fahZc1L7C- $\&$ sig $=$ g7gLcQOV-iq4Cky5tCyKLghiF4\&redir_esc $=y \# v=$ onepage \&q\&f=false

Rahmanto, M. A., \& Bunyamin, B. (2020). Efektivitas Media Pembelajaran Daring melalui Google Classroom. Jurnal Pendidikan Islam, 11(2). https://doi.org/https://doi.org/10.22236/jpi.v11i2.5974

Thomas, M. S. C., \& Rogers, C. (2020). Education, the science of learning, and the COVID-19 crisis. Springer, 49, 87-90. https://doi.org/https://doi.org/10.1007/s11125020-09468-z

Wijaya, A., Retnawati, H., Setyaningrum, W., Aoyama, K., \& Sugiman. (2019). Diagnosing Students' Learning Difficulties In The Eyes Of Indonesian Mathematics Teachers. Journal on Mathematics Education, 10(3), 357-36. https://doi.org/https://doi.org/10.22342/jme.10.3.7798.357-364 